\title{
O PAPEL DOS DISCENTES DO CURSO DE ENGENHARIA DE MINAS NA DIVULGAÇÃO DE INFORMAÇÕES DO SETOR MINERAL: UM ESTUDO DE CASO DA UFC EM CRATEÚS
}

DOI: 10.37702/2175-957X.COBENGE.2021.3450

Domingos Sávio Oliveira Timbó Vasconcelos - saviovasconcelos@alu.ufc.br Universidade Federal do Ceará Rua Vicente Alves do Vale S/N 63750-000 - Tamboril - CE

Rafael Tavares Landim - landim.raafaell@gmail.com Universidade Federal do Ceará

Rua Santos Dumont 357

63500-146 - Iguatu - CE

Andreza Rafaela Morais Pereira - andrezamorais00@gmail.com UFC

Rua Francisco Zeca Silva 100

58410-817 - Campina Grande - PB

Tiany Guedes Cota - tianycota@crateus.ufc.br

Universidade Federal do Ceará

Rua Clovis Bevilaqua 1188

63700-155 - Crateús - CE

Resumo: A mineração é uma atividade que visa a extração dos recursos minerais da crosta terrestre, para que sejam utilizados como matéria-prima em diversos setores industriais. Logo, nosso dia a dia está intimamente ligado aos minerais e seus produtos de transformação. No entanto, as informações sobre este setor são pouco difundidas, o que faz com que a sociedade tenha pouco conhecimento sobre a atividade. Dessa forma, o presente trabalho teve como objetivo realizar um estudo sobre o papel do estudante de Engenharia de Minas na difusão de informações sobre a mineração. Através do projeto de extensão "Por Dentro da Mineração" da Universidade Federal do Ceará campus de Crateús, foram realizadas palestras e atividades educativas sobre mineração em turmas de alunos do terceiro ano do ensino médio das escolas públicas da região de Crateús, no 
Ceará. O projeto alcançou aproximadamente 290 alunos, em 5 escolas de 3 municípios da região. Foi feita uma avaliação comparativa entre o conhecimento dos alunos sobre a mineração antes e após a realização das atividades, onde foi constatado uma evolução considerável. Alguns alunos ingressantes no curso de Engenharia de Minas da UFC em Crateús relataram que a participação nas atividades do projeto influenciou na escolha do curso. Os resultados mostraram que a divulgação de informações e o esclarecimento de dúvidas sobre o setor mineral, sobretudo pelos estudantes da área, são de grande relevância no processo de tornar o setor mineral conhecido, conforme a sua importância.

Palavras-chave: Extensão universitária. Divulgação de informações. Engenharia de Minas. Setor mineral. 


\section{O PAPEL DOS DISCENTES DO CURSO DE ENGENHARIA DE MINAS NA DIVULGAÇÃO DE INFORMAÇÕES DO SETOR MINERAL: UM ESTUDO DE CASO DA UFC EM CRATEÚS}

\section{INTRODUÇÃO}

A mineração pode ser definida como o conjunto de atividades que visam disponibilizar bens minerais de valor econômico da crosta terrestre para as diversas cadeias produtivas, possuindo relação direta com a evolução da humanidade. De acordo com Lima (2013), esta atividade é uma das mais antigas dentre os modos de produzir riquezas e materiais, sendo 300.000 a.C. a data aproximada da primeira atividade de extração mineral que os historiadores têm conhecimento. Até hoje, a atividade é essencial para o desenvolvimento da civilização, inclusive no Brasil, onde o setor mineral tem relevância econômica e estratégica para vários outros setores, como a construção civil e para o desenvolvimento de novas tecnologias (SILVA et al., 2015; PAMPLONA e PENHA, 2018).

Valadão e Araújo (2007) afirmam que os desafios técnicos, sociais e ambientais que se colocam para a indústria mineral requerem o aperfeiçoamento e o contínuo desenvolvimento de novos métodos de mineração e de processamento que permitam minimizar os impactos ao meio ambiente, e ao mesmo tempo, fornecer os recursos necessários para a economia.

Segundo Castro et al. (2015), a mineração não se destaca apenas por ser uma indústria de base, mas também por sua condição de impulsionar novas e outras atividades econômicas. Por ser uma atividade de longo prazo, propicia o desenvolvimento das comunidades localizadas em seu entorno. Quando implementada e desenvolvida de maneira responsável, dentro das premissas técnicas modernas e legais, causa impactos ambientais que podem ser reduzidos de maneira significativa.

No entanto, por se tratar da extração de recursos minerais não renováveis, a mineração geralmente é vista como uma atividade altamente impactante e não sustentável. Este fato contribui para que grande parte da população tenha uma percepção negativa ou até mesmo indiferente do setor, considerando, também, a visão incompleta da cadeia produtiva, em que a importância das indústrias que proporcionam os produtos de nosso cotidiano é reconhecida, mas esses produtos não são relacionados com as matérias-primas minerais e sua exploração (CASTRO et al., 2005; SILVA et al., 2015).

Dessa forma, um dos grandes desafios da indústria mineral é torná-la conhecida e assimilada como campo essencial do setor industrial. Castro et al. (2005) apresentam os resultados de uma pesquisa feita com estudantes de ensino médio e superior que comprova a ausência de conhecimento do público sobre a área mineral. O trabalho enfatiza que os profissionais do setor mineral têm a tarefa de facilitar o acesso ao conhecimento e disseminar informações técnicas de uma forma compreensível. Isso também se aplica aos estudantes da área, que possuem aptidão para contribuir na difusão destas informações. Nesse sentido, Loures et al. (2016) apresentaram um projeto na qual são desenvolvidas atividades educativas sobre mineração em escolas públicas das cidades de Ouro Preto e Mariana, em Minas Gerais, visando destacar a importância da atividade mineral para a sociedade.

Considerando que no ensino atual não é comum que o conhecimento sobre a indústria mineral seja levado às crianças e jovens, o presente trabalho tem como objetivo realizar um estudo sobre o papel do estudante de Engenharia de Minas na difusão de informações sobre a mineração. O trabalho faz parte do projeto de extensão "Por dentro da Mineração", que teve como público alunos do terceiro ano do ensino médio das escolas 
públicas da região de Crateús, no Ceará, com o propósito de apresentar a mineração aos alunos e, de modo combinado, realizar atividades integrando temas do setor mineral à temas que são cobrados no ENEM, além de divulgar o curso de Engenharia de Minas da UFC em Crateús.

\section{METODOLOGIA}

\subsection{Projeto Por Dentro da Mineração}

O desenvolvimento do projeto foi dividido em duas fases bem definidas. Na primeira fase, foram realizadas apresentações nas escolas em forma de palestras. Já na segunda fase, foi selecionada uma única escola, e fundamentou-se na realização de atividades integradas entre temas relacionados à mineração e eixos cognitivos cobrados no Exame Nacional do Ensino Médio (ENEM).

\section{Palestras}

Incialmente, foi decidido entre os discentes participantes do projeto e a professora orientadora o conteúdo padrão das apresentações, sendo definido na seguinte sequência:

i. Informações relacionadas à universidade na qual o projeto está inserido (localização, cursos existentes e site);

ii. Informações sobre o curso de Engenharia de Minas e suas áreas de estudo;

iii. Finalidade e importância da mineração;

iv. Fases da mineração;

v. Contexto da mineração no Brasil e no Ceará;

vi. Vídeos relacionados a mineração.

Após a etapa de planejamento, buscou-se o contato com a coordenação das escolas de ensino público da região de Crateús, e verificou-se a viabilidade de realização do projeto, a sua disponibilidade, sendo definido datas e horários das visitas. Desse modo, organizouse os materiais didáticos, nos quais foram utilizadas as maquetes e minerais do Laboratório de Geologia da UFC em Crateús, visando tornar a apresentação mais dinâmica e atrativa para os alunos. A criação de uma conta no Instagram para o projeto foi outro recurso utilizado como atrativo para os alunos e para o público em geral, e também como meio de divulgação das ações realizadas.

Para conhecer a percepção prévia dos alunos sobre a mineração, elaborou-se um questionário com perguntas simples sobre o tema. O questionário foi respondido antes e após a apresentação, para que também fosse possível avaliar o acréscimo de conhecimento e/ou a mudança de pensamento em relação aos assuntos abordados na palestra. As perguntas abordadas no questionário são estas descritas abaixo, as opções de resposta eram: "Sim", "Não", "Talvez" e "Não sei".

i. A mineração é necessária para a humanidade?

ii. O Brasil apresenta potenciais para mineração?

iii. No Ceará, o mercado de trabalho é ativo nessa área?

iv. A mineração está envolvida na fabricação dos componentes de uma lapiseira?

v. A mineração, direta ou indiretamente, faz parte do seu cotidiano?

Em seguida, os dados foram tratados, permitindo uma análise comparativa entre o conhecimento sobre a indústria mineral antes e após as apresentações realizadas com os estudantes. 


\section{Atividades integradas}

A princípio, fez-se uma revisão à cerca dos eixos cognitivos e das competências cobradas no ENEM, a fim de conectá-las às atividades a serem elaboradas. Foi construído um cronograma contendo datas, descrições das atividades e as competências correspondentes, objetivando uma maior organização do trabalho e a apresentação do cronograma à coordenação da escola.

Posteriormente, definiu-se que o desenvolvimento das atividades se daria, primeiramente, com uma explicação sobre o conteúdo proposto, utilizando recursos audiovisuais e o quadro, seguida de aplicações do conteúdo nas áreas de estudo da mineração. Para melhor fixação da teoria, foram elaborados alguns exercícios, e buscouse questões do ENEM de anos anteriores sobre o tema apresentado. A participação das atividades foi definida como opcional, sendo que as mesmas deveriam ser realizadas em um horário extracurricular. Dessa forma, possíveis adaptações no cronograma poderiam ser feitas, visando se adequar à disponibilidade dos participantes.

Objetivando conhecer a percepção dos alunos após a realização das atividades, foi criado um formulário virtual com perguntas relacionadas à efetividade das atividades realizadas. $O$ formulário continha três perguntas:

i. As atividades desenvolvidas contribuíram com a aprendizagem de conteúdos relacionados ao ENEM?;

ii. As atividades possibilitaram o conhecimento sobre alguma(s) área(s) de estudo da mineração?

iii. As atividades desenvolvidas e a interação com estudantes de ensino superior possibilitaram o conhecimento prévio sobre a universidade?

As opções de resposta eram: "Sim" e "Não". Um espaço para comentários e sugestões também foi adicionado ao formulário.

\subsection{Papel dos estudantes na divulgação de informações}

Buscando completar a coleta de informações a respeito da relevância da divulgação das informações sobre mineração, assim como analisar a influência do projeto na escolha dos alunos ao curso de Engenharia de Minas, criou-se um terceiro questionário a ser respondido virtualmente. Este foi aplicado aos alunos que ingressaram no curso de Engenharia de Minas em 2020 e participaram de pelo menos uma atividade do projeto no ano de 2019.

O questionário teve as seguintes perguntas:

i. $\quad$ Qual tipo de atividade do projeto você participou?;

ii. A sua participação nessas atividades influenciou na sua escolha ao curso de Engenharia de Minas? Se possível, justifique.

iii. Ao final, foi adicionado um espaço para que os alunos fizessem comentários.

\section{RESULTADOS E DISCUSSÃO}

\subsection{Palestras}

Foram realizadas palestras para os alunos de cinco escolas, sendo três palestras no município de Crateús, uma palestra no município de Tamboril e uma palestra no município de Novo Oriente. Em relação ao questionário, optou-se por não o aplicar em alguns casos, devido ao curto tempo disponível. A Tabela 1 apresenta as escolas na qual foram feitas as apresentações, assim como algumas informações referentes ao desenvolvimento delas. 
Tabela 1 - Informações das palestras realizadas nas escolas do município de Crateús, Tamboril e Novo Oriente.

\begin{tabular}{|c|c|c|c|}
\hline Escola & Município & $\begin{array}{c}\text { Local da } \\
\text { apresentação }\end{array}$ & Questionário \\
\hline EEFM Lourenço Filho & Crateús & Na própria escola & Respondido \\
\hline CE Regina Pacis & Crateús & Na própria escola & Não respondido \\
\hline EEMTI Lions Club & Crateús & Na própria escola & Respondido \\
\hline EEEP Antônio Mota Filho & Tamboril & Na própria escola & Não respondido \\
\hline $\begin{array}{l}\text { EEEP Maria Eudes Bezerra } \\
\text { Veras }\end{array}$ & Novo Oriente & $\begin{array}{l}\text { UFC - Campus } \\
\text { Crateús }\end{array}$ & Não respondido \\
\hline
\end{tabular}

Fonte: Elaborado pelos autores (2021)

Estima-se que aproximadamente 290 alunos assistiram às palestras do projeto, com base na quantidade de alunos por turma, que variou em cada escola. O número de alunos que responderam os questionários foi de 149. Nas escolas visitadas, as apresentações ocorreram com as turmas reunidas no auditório da escola (Figura 1), com exceção da EEFM Lourenço Filho, em que foram feitas apresentações nas salas de cada turma. A conta no Instagram obteve 137 seguidores até o final do período de atuação do projeto no ano de 2019, sendo utilizada, principalmente, para a divulgações das ações realizadas.

Figura 1 - Palestras realizadas na EEEP Antônio Mota Filho (a) e EEMTI Lions Club (b).

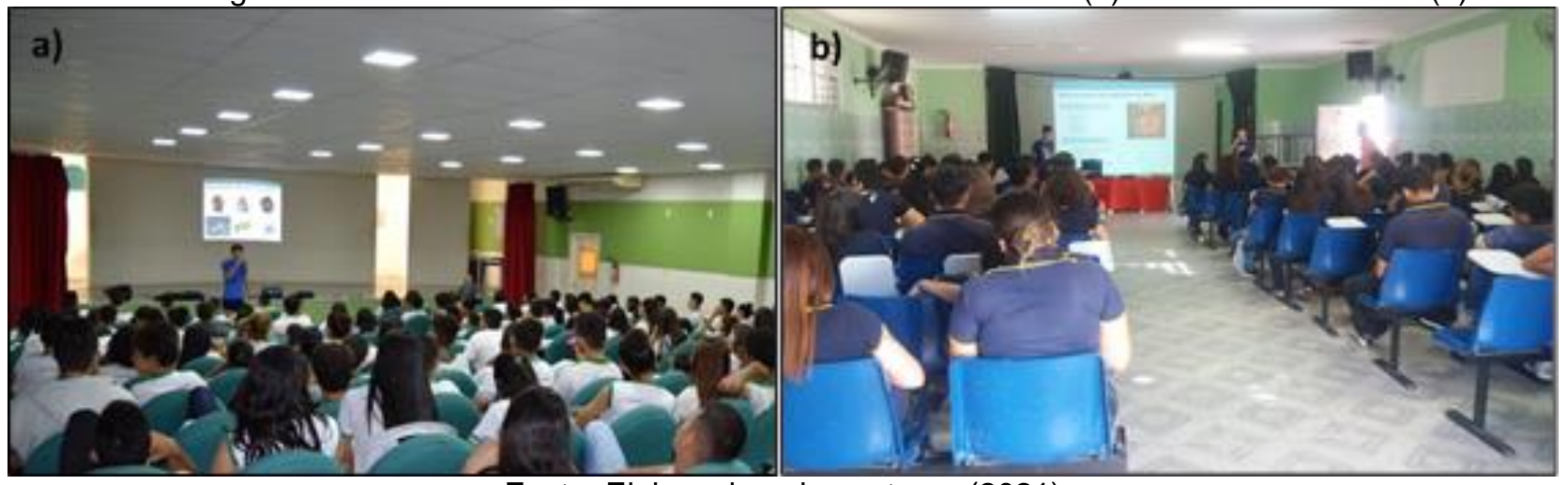

Fonte: Elaborado pelos autores (2021)

Além das palestras realizadas nas escolas, foi feita uma apresentação durante uma visita de alunos da EEEP Maria Eudes Bezerra Veras ao Campus da UFC/Crateús (Figura 2). Esta visita foi promovida pela própria escola, com o objetivo de apresentar aos alunos, os cursos oferecidos na unidade acadêmica. Durante esta visita, houveram apresentações de todos os cursos, sobretudo do curso de Engenharia de Minas, em que o conteúdo apresentado foi o mesmo das palestras convencionais do projeto, porém exposto de forma resumida, e também acrescido de exposição de maquetes e amostras minerais do Laboratório de Geologia. Sendo assim, esta apresentação foi incluída como uma atividade do projeto. 
Figura 2 - Fotos da apresentação feita aos alunos EEEP Maria Eudes Bezerra Veras.

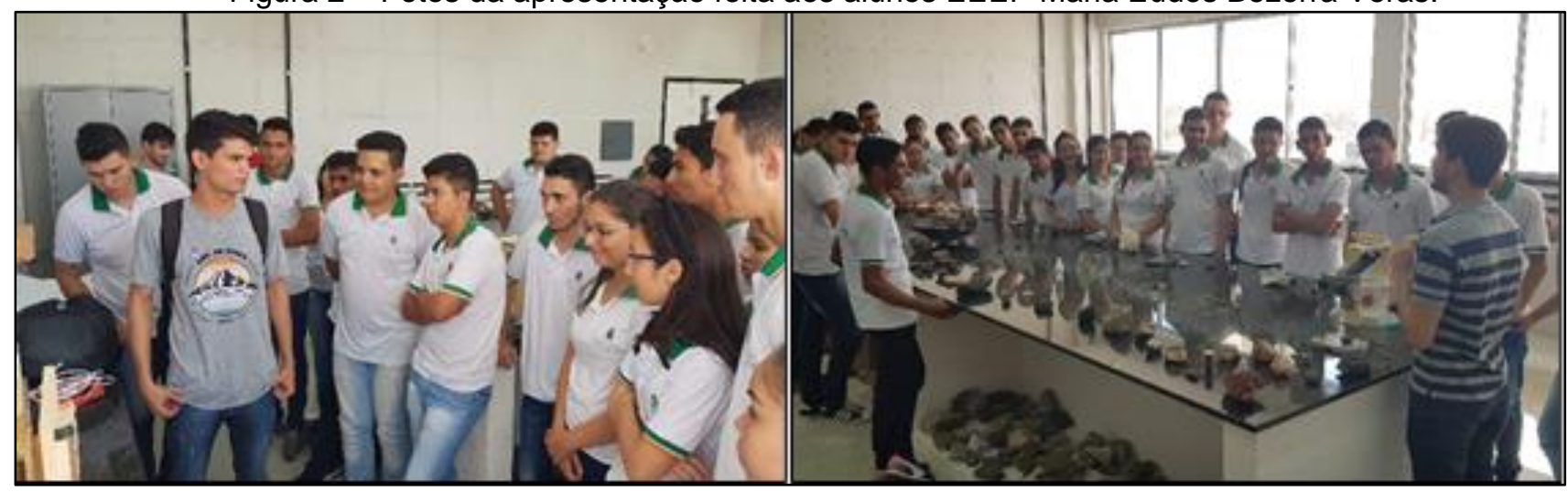

Fonte: Elaborado pelos autores (2021)

As Figuras 3 a 6 apresentam os resultados dos questionários respondidos pelos 149 alunos antes e depois das apresentações feitas nas escolas. A Figura 3 apresenta os resultados da primeira questão, "A mineração é necessária para a humanidade?", e da segunda questão, "O Brasil apresenta potenciais para mineração?". É possível observar que antes das apresentações aproximadamente $65 \%$ e $54 \%$ dos alunos responderam "sim", enquanto que $9 \%$ e $21 \%$ responderam "Não sabem", respectivamente. Após a palestra, todos os alunos deram uma resposta positiva para as perguntas realizadas. A partir das duas primeiras questões, percebe-se uma evolução por parte dos alunos, no que diz respeito ao conhecimento básico sobre o tema apresentado, visto que, nas apresentações foi ressaltado sobre a importância da mineração na vida humana, assim como sobre as principais reservas de bens minerais brasileiras em comparação com o mundo.

Figura 3 - Resultados da primeira e segunda questão do questionário respondido pelos alunos das escolas participantes das palestras.

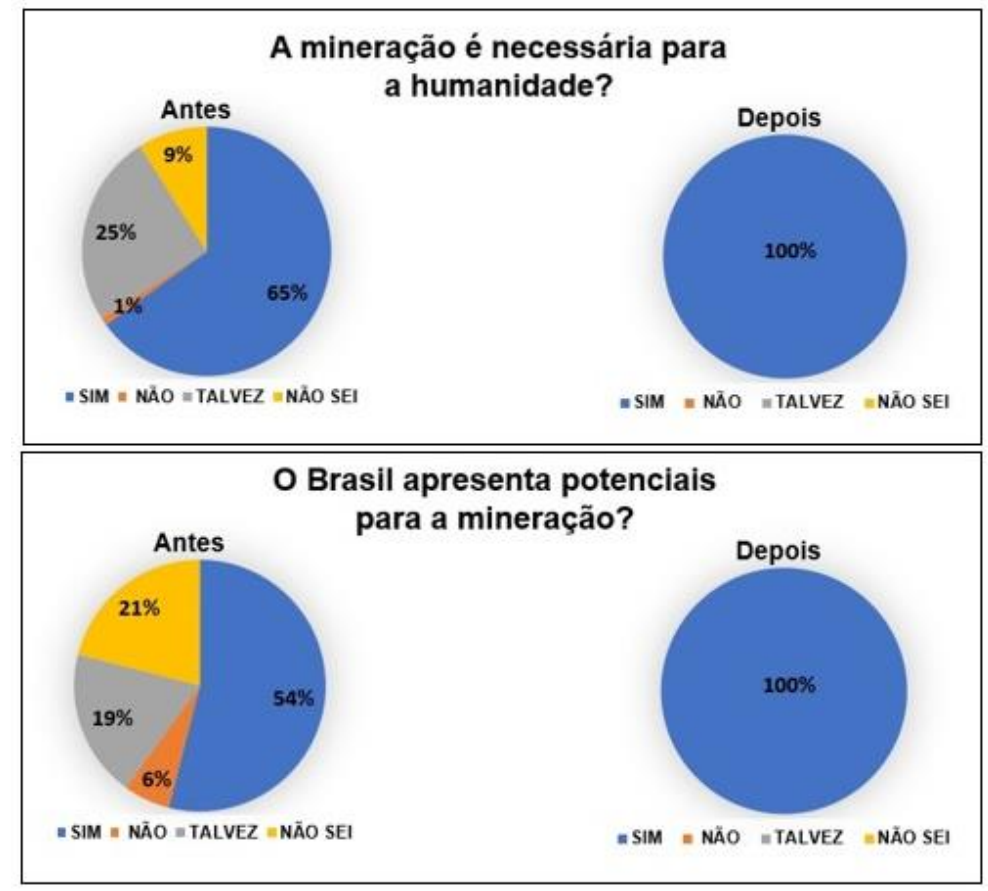

Fonte: Elaborado pelos autores (2021) 
A Figura 4 apresenta o resultado da terceira questão, "No Ceará, o mercado de trabalho é ativo nessa área?", sendo a pergunta que obteve o menor percentual de respostas positivas antes das apresentações, correspondendo a apenas $16 \%$ dos alunos tinham conhecimento da atuação mineral no estado do Ceará. Na palestra, foi evidenciado que o Ceará não é um estado com tradição em mineração, porém, apresenta mercado ativo na produção de minerais e rochas industriais, além de ter reservas promissoras de bens minerais a nível nacional. A maioria dos alunos desconhecia estas informações, após as apresentações aproximadamente $88 \%$ dos alunos mudaram seu ponto de vista.

Figura 4 - Resultado da terceira questão do questionário respondido pelos alunos das escolas participantes das palestras.

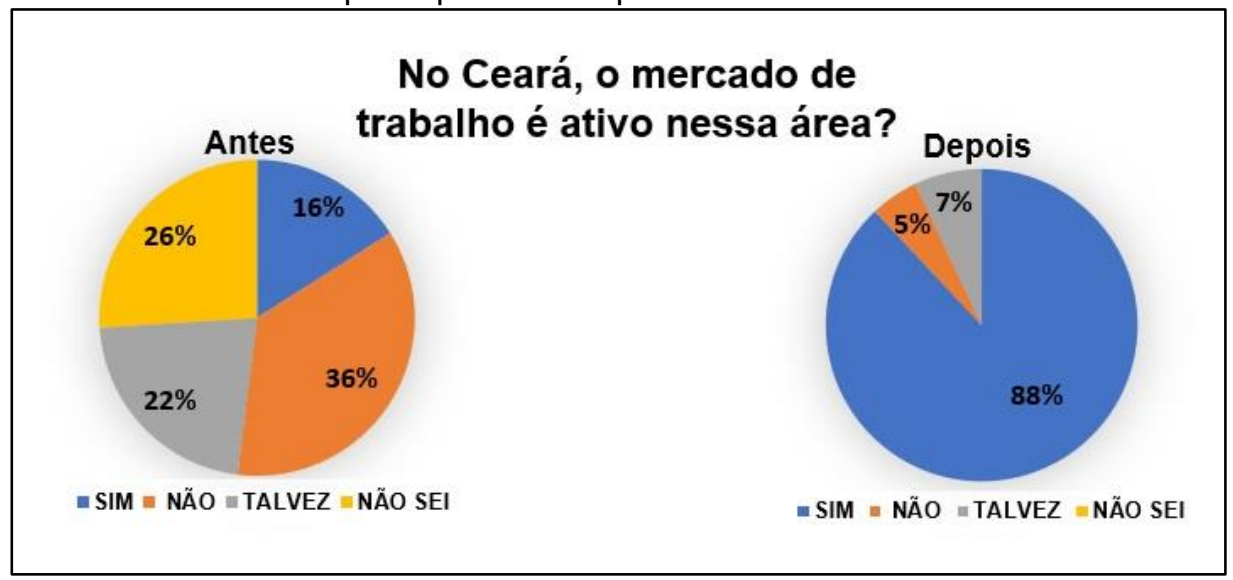

Fonte: Elaborado pelos autores (2021)

A Figura 5 apresenta o resultado da quarta questão, "A mineração está envolvida na fabricação dos componentes deste objeto?", e a Figura 6 da quinta questão, "A mineração, direta ou indiretamente, faz parte do seu cotidiano?". Anterior as apresentações $75 \%$ e $55 \%$ dos alunos sabiam que a mineração compõe grande parte dos objetos que usamos diariamente, fazendo parte do nosso dia-a-dia. Enquanto que, $14 \%$ e $11 \%$, respectivamente, não sabem responder essas questões. Após as apresentações notou-se que a maioria dos alunos conseguiram fixar o fato de que a mineração está totalmente presente no dia a dia da sociedade, sendo a principal provedora de matéria-prima para a fabricação de diversos objetos que utilizamos cotidianamente.

Figura 5 - Resultado da quarta e quinta questão do questionário respondido pelos alunos das escolas participantes das palestras.

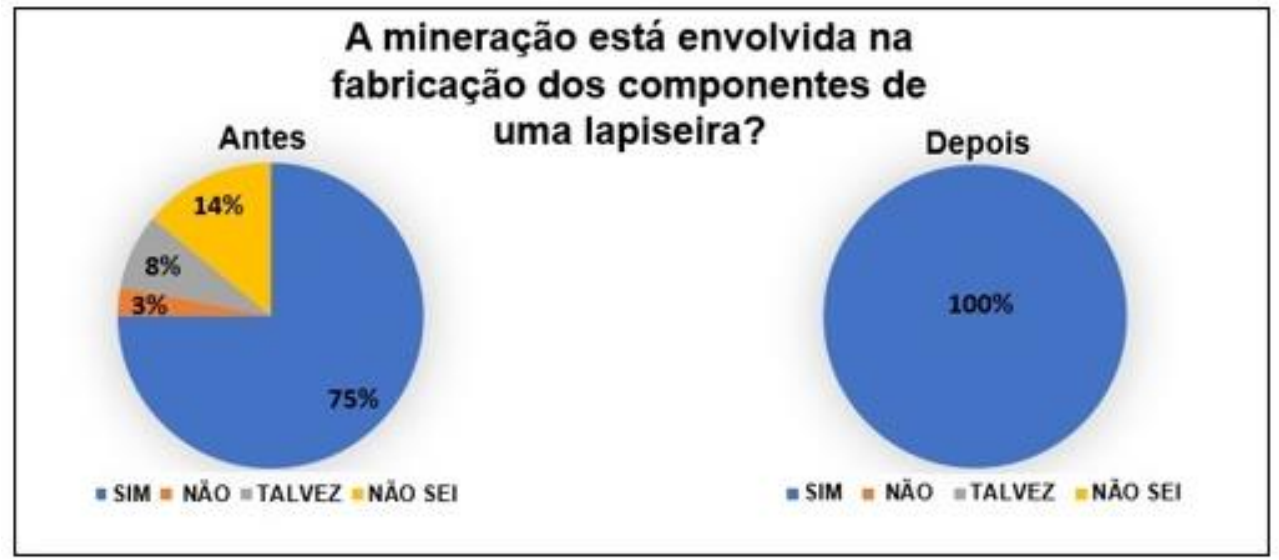

Fonte: Elaborado pelos autores (2021) 
Figura 6 - Resultado da quarta e quinta questão do questionário respondido pelos alunos das escolas participantes das palestras.

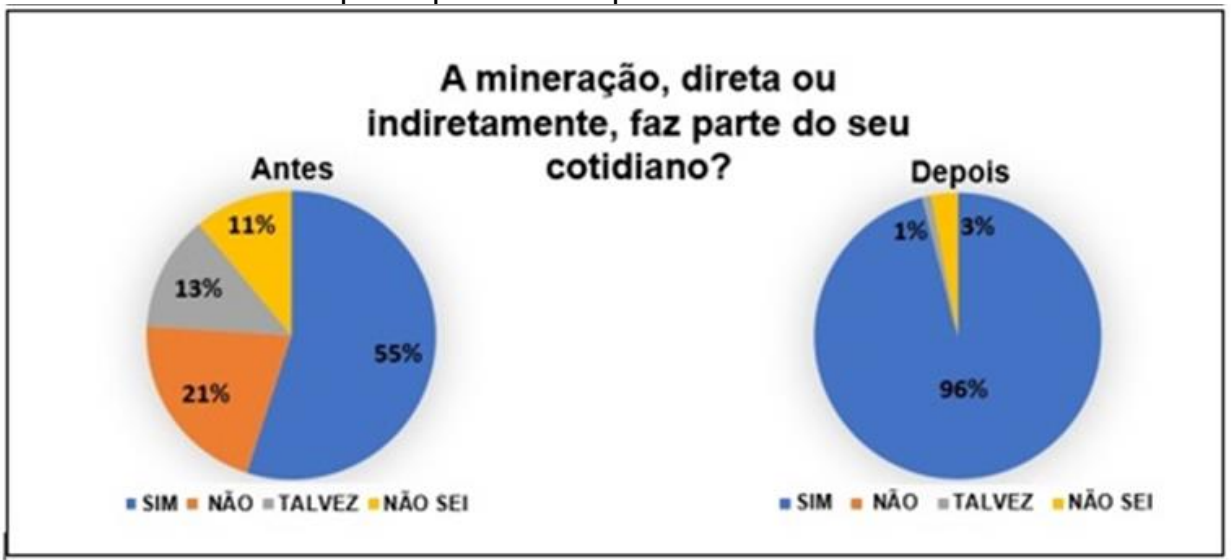

Fonte: Elaborado pelos autores (2021)

Os resultados encontrados condizem com os apresentados por Cordeiro et al. (2019), onde os autores afirmam que dentro da escola não há muito entendimento sobre a cadeia produtiva da mineração e as aplicações dos produtos obtidos para manutenção e desenvolvimento da sociedade, sendo que a interação entre os alunos possibilita um contato maior, difundindo os conceitos da mineração de maneira didática entre os estudantes.

No conteúdo apresentado, foram enfatizados todos os assuntos abordados em cada pergunta, o que justifica o alto percentual de respostas positivas nos questionários posteriores às palestras. Isso nos mostra que os alunos estiveram atentos às informações passadas e conseguiram apropriar-se delas. Dessa forma, o objetivo desta fase do projeto foi alcançado.

\subsection{Atividades Integradas}

O cronograma com a descrição das atividades está representado na Tabela 2. Este foi apresentado à coordenação da escola EEMTI Lions Club em que as atividades foram desenvolvidas aos sábados devido à falta de horários e datas disponíveis que atendessem aos alunos da escola e aos desenvolvedores do projeto.

Foram realizados dois encontros com os alunos, devido ao curto prazo até a data da prova do ENEM. Logo, para que se conseguisse repassar o máximo do conteúdo planejado, foram trabalhados, no mesmo dia, temas de diferentes atividades que apresentavam correlação entre si. 
Tabela 2 - Cronograma e descrição das atividades integradas realizadas na EEMTI Lions Club

Competências ENEM

Atividade 1

Resolver situação-problema que envolva conhecimentos geométricos de espaço e forma.

Atividade 2

Atividade 3

Atividade 4

diferentes representações gráficas e cartográficas dos espaços geográficos.

Resolver problema com dados apresentados em tabelas ou gráficos.

Atividade 5

Avaliar impactos em ambientes naturais decorrentes de atividades sociais ou econômicas, considerando interesses contraditórios.

\section{Desenvolvimento}

Resolução de problemas de área e volume de formas geométricas. Ex.: Calcular o volume de uma pilha pulmão e calcular a capacidade de carga de um caminhão.

Resolução de problemas envolvendo cálculo de escala e unidades de medida.

Estudo sobre geologia e os tipos de rochas e minerais.

Interpretação de mapas geológicos.

Apresentação e discussão sobre Meio Ambiente e Mineração.

Fonte: Elaborado pelos autores (2021)

No primeiro encontro com os alunos, a atividade 1 foi realizada integralmente e sem a combinação com outra atividade. Os assuntos das atividades 2,3 e 4, foram abordados na mesma ocasião, integrados ao tema cartografia (Figura 7). Na oportunidade, foram estudados conceitos sobre o assunto, somados a análises de mapas geológicos e seus elementos cartográficos, com exercícios referentes às escalas observadas em cada mapa.

Figura 7 - Atividade de cartografia desenvolvidas na EEMTI Lions Club

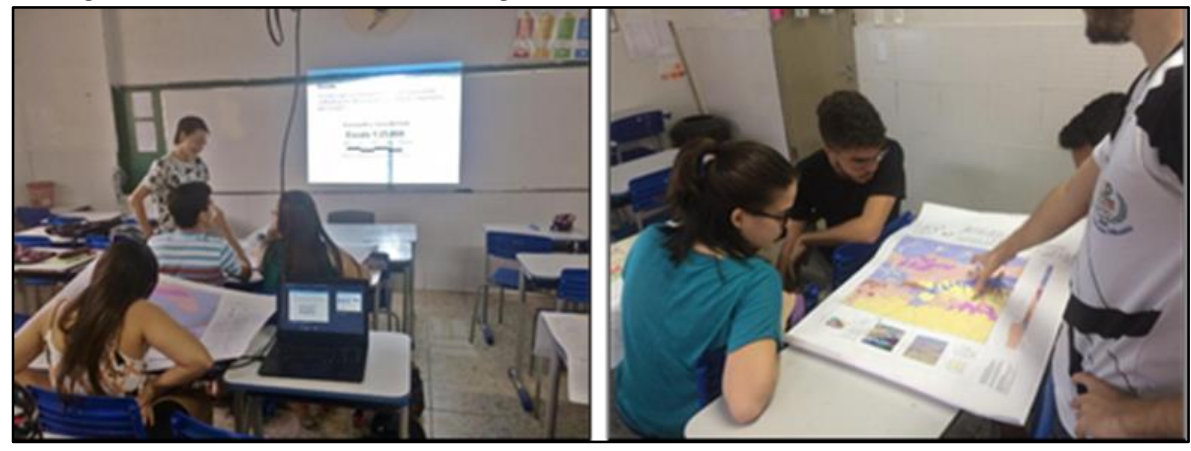

Fonte: Elaborado pelos autores (2021) 
Esta fase do projeto contou com a participação de 16 alunos. Considera-se um bom número, visto que foi possível desenvolver as atividades da maneira esperada. Um maior número de alunos poderia causar dificuldades na condução da turma ou dispersões, levando em conta que os integrantes do projeto não possuíam experiência em docência. $O$ formulário de avaliação das atividades foi respondido por 10 alunos e os resultados estão apresentados na Figura 8.

Figura 8 - Resultados quantitativos da percepção dos alunos sobre as atividades integradas realizadas

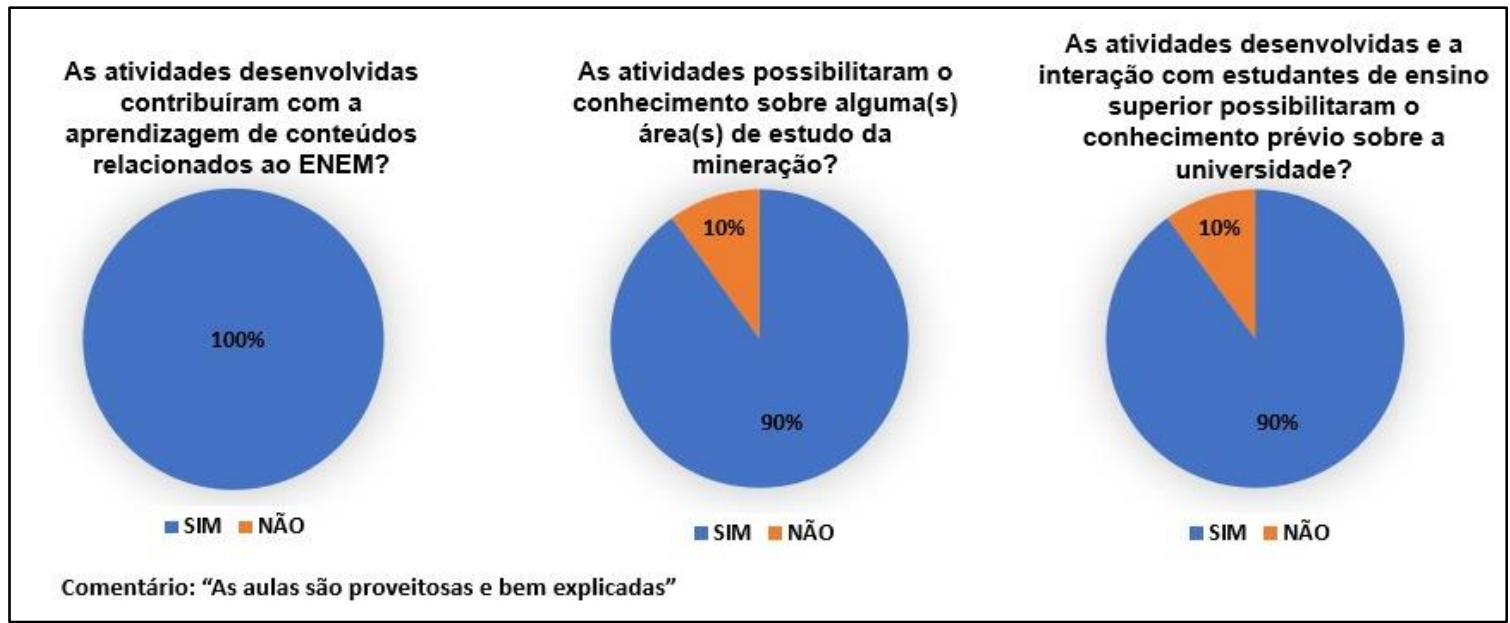

Fonte: Elaborado pelos autores (2021)

Foram obtidos bons indicadores em relação às atividades, tendo em vista a maioria de respostas positivas nas três perguntas do formulário, que remetem, justamente, aos objetivos pretendidos.

\subsection{Papel dos estudantes na divulgação de informações}

Ao todo, 7 alunos que ingressaram no curso de Engenharia de Minas da UFC em Crateús no ano de 2020, participaram de pelo menos uma atividade do projeto no ano anterior. Destes, 4 responderam ao formulário que tinha como objetivo analisar a influência do projeto na escolha dos alunos ao curso. Dos alunos que responderam ao formulário, um aluno participou de uma palestra, um aluno participou de uma palestra e de uma atividade integrada, e dois alunos participaram da visita ao campus.

Quando perguntados se a participação nas atividades influenciou na escolha ao curso, responderam:

"Não, eu já tinha escolhido esse curso antes."

"Sim, pois fez com que eu enxergasse o curso de uma forma diferente"

"Sim, uma vez que foi o principal meio que obtive para esclarecer as minhas dúvidas, assim como, foi o único método que chamou de forma bastante significativa a minha atenção."

"Sim. Fiquei muito admirado com a variabilidade de minerais e as riquezas que o solo apresenta"

No espaço destinado a comentários, 3 alunos deixaram relatos: 
"Foi uma boa iniciativa iniciar esse projeto e tentar mostrar para a comunidade e aos jovens sobre a importância tanto da UFC quanto do curso de Engenharia de Minas."

"Muito bom, pois instruiu de forma precisa e interativa sobre a mineração"

"O que me chamou mais atenção foi as maquetes confeccionadas, visto que demonstrava os processos básico da mineração, além das excelentes explicações dos discentes. Outro fator contribuinte foi a apresentação do laboratório de Mineralogia, onde percebi que através do curso de engenharia de minas eu poderia estar estudando a terra de maneira mais 'sólida'."

Então, notou-se que as metodologias adotadas foram eficientes, principalmente quanto à utilização de materiais didáticos como maquetes e amostras de minerais, na qual tornaram as apresentações mais atrativas. As respostas do formulário reforçam os resultados das análises anteriores, mostrando que o setor mineral e o curso de Engenharia de Minas são pouco conhecidos, e que a difusão de informações e o esclarecimento de dúvidas, sobretudo pelos estudantes da área, são de grande importância para que se consiga contornar tal fato.

\section{CONSIDERAÇÕES FINAIS}

As palestras do projeto alcançaram aproximadamente 290 alunos, divididos em 5 escolas de 3 municípios da região de Crateús. A avaliação comparativa entre 0 conhecimento sobre o setor mineral antes e após as apresentações foi feita com 149 estudantes, por meio dos resultados do questionário passado. Foi observado uma evolução do conhecimento sobre o tema apresentado, que inclui informações sobre a importância da mineração para a humanidade, como ela está presente no nosso cotidiano e como ela se apresenta no Ceará e no Brasil.

Foram realizadas 2 atividades integrando eixos cognitivos do ENEM com temas estudados no setor mineral. A quantidade de atividades foi menor que o planejado devido à falta de disponibilidade comum entre os alunos participantes e os desenvolvedores do projeto. Sendo assim, foram feitas adaptações no conteúdo a ser trabalhado, para a obtenção de uma maior efetividade. A análise feita ao término desta fase do projeto mostra que a maioria dos participantes considerou que as atividades contribuíram no acréscimo de conhecimento sobre temas do ENEM e da mineração.

A influência do projeto na escolha dos alunos ao curso de Engenharia de Minas (UFC) foi verificada por meio de um levantamento feito com alguns alunos ingressantes no presente ano, onde estes declararam terem passado a ver o curso de uma maneira diferente após a participação no projeto, destacando a utilização de materiais atrativos e o esclarecimento de dúvidas como fatores contribuintes.

A presença do projeto nas redes sociais foi discreta, no entanto, acredita-se que este meio, como um instrumento informativo, é uma boa alternativa para um alcance maior do público. A tendência pela utilização de metodologias que facilitam o aprendizado e o frequente uso de recursos didáticos atrativos também podem ser estratégias para a melhoria deste projeto e de outras ações de mesma natureza. 


\section{Agradecimentos}

Agradecemos pela receptividade e disponibilidade de todas as escolas em que as atividades do projeto foram desenvolvidas; à Universidade Federal do Ceará pela oportunidade do desenvolvimento da extensão universitária; e à professora Tiany Guedes Cota pelo apoio e orientação do projeto.

\section{REFERÊNCIAS}

CASTRO, N. F.; CARVAlHO, E. A.; CARRISSO, R. C. C. Estudo da percepção da mineração de estudantes de ensino médio e universitário: papel dos profissionais na divulgação de informação. Centro de Tecnologia Mineral (CETEM) / MCT - Rio de Janeiro, 2005.

CASTRO, P.T.A., NALINI JÚNIOR, H.A., LIMA, H.M., Entendendo a Mineração no Quadrilátero Ferrífero. 1.ed. Belo Horizonte: Ecológico - Comunicação e Meio Ambiente, 2015.

CORDEIRO, I. S.; CASTRO, G. A. O.; CARVALHO, L. F. P.; MARTINS, L. L. O.; REIS, E. L. Mineração para escolas: ênfase na cadeia produtiva. In: XXVIII Encontro Nacional de Tratamento de Minérios e Metalurgia Extrativa, Belo Horizonte, 2019.

LIMA, Helder Cordeiro. A trajetória do setor mineral no município de Pedra Lavrada - PB: uma análise das ações públicas para pensar o desenvolvimento. 2013. 127 f. Dissertação (Mestrado em Desenvolvimento Regional) - Universidade Estadual da Paraíba, Campina Grande, 2013.

LOURES, Pedro Superbi et al. Mineração para Escolas - Desenvolvimento de práticas pedagógicas sobre mineração para crianças e jovens. XLIV Congresso Brasileiro de Educação em Engenharia, 2016.

PAMPLONA, João Batista; PENHA, Ana Carolina. A política de inovação para o setor mineral no Brasil: uma análise comparativa com a Suécia centrada na interação dos agentes envolvidos. Cad. EBAPE.BR, v. 17, n 4, Rio de Janeiro, 2018.

SILVA, A. R. B. Mineração na Escola. Centro de Tecnologia Mineral - CETEM, Rio de Janeiro, 2015.

VALADÃO, G.E.S.; ARAUJO, A.C. Introdução ao Tratamento de Minérios. Belo Horizonte: Editora da UFMG, 2007. 


\title{
THE ROLE OF MINING ENGINEERING STUDENTS IN THE DISCLOSURE OF MINERAL SECTOR INFORMATION: A CASE STUDY FROM UFC IN CRATEÚS
}

\begin{abstract}
Mining is an activity that aims to extract mineral resources from the earth's crust, so that they can be used as raw material in several industrial sectors. Therefore, our daily lives are closely linked to minerals and their transformation products. However, information about this sector is not widely disseminated, which means that society has little knowledge about the activity. Thus, the present study aimed to conduct a study on the role of the Mining Engineering student in the dissemination of information about mining. Through the extension project "Por Dentro da Mineração" at the Federal University of Ceará in campus of Crateús, lectures and educational activities on mining were carried out with classes of students of the third year of high school in public schools in the region of Crateús in Ceará. The project reached approximately 290 students, divided into 5 schools in 3 municipalities in the region. A comparative assessment was made between the students' knowledge of mining before and after the activities were carried out, where a considerable evolution was found. Some students entering the mining engineering course reported that participation in the project activities influenced their choice of course. The results showed that the dissemination of information and the clarification of doubts about the mineral sector, especially by students in the area, are of great importance in the process of making the sector known, according to its importance.
\end{abstract}

Keywords: University extension. Disclosure of information. Mining Engineering. Mineral sector. 